\title{
Effectiveness of a Patient-Centered Weight Management Model in a Community Pharmacy: An Interventional Study
}

This article was published in the following Dove Press journal: Patient Preference and Adherence

\author{
Jesús Gómez-Martinez' \\ Elsa López-Pintor (iD ${ }^{2}$ \\ Blanca Lumbreras iD ${ }^{3}$ \\ 'Pharmacy Jesús C. Gómez Martínez, \\ Barcelona 0804I, Spain; ${ }^{2}$ Department of \\ Engineering, Area of Pharmacy and \\ Pharmaceutical Technologies, Miguel \\ Hernández University, Alicante 03550 , \\ Spain; ${ }^{3}$ Department of Public Health, \\ History of Science and Gynecology, \\ Miguel Hernández University, CIBER in \\ Epidemiology and Public Health, Alicante \\ 03550, Spain
}

Purpose: The aim of this study was to evaluate the provision of a professional pharmaceutical patient-centered model in a weight management program and optimization of the medication in a Spanish community pharmacy.

Patients and Methods: This was a single-group intervention study with a mean follow-up period of 8.2 months (sd 2.3). Patients $\geq 18$ years old seeking to lose weight or improve eating habits were recruited. On the first visit, the pharmacist collected patients' sociodemographic and anthropometric variables, dietary history and lifestyle habits, biochemical measurements and other clinical and therapeutic data. The intervention was based on the Spanish Society of Community Pharmacy recommendations for diet and exercise and for pharmacotherapy management. The follow-up included a two-month visit and a final visit. Results: A total of 330 patients were included ( $80 \%$ women; mean age 51.3 years old (sd 15.3)). A statistically significant reduction in anthropometric measurements (weight, BMI, and waist circumference) and a statistically significant increase in the number of patients with normal cholesterol and LDL-cholesterol $(p<0.001)$ were observed at two-month visit compared with first visit $(\mathrm{p}<0.001)$. The number of patients with normal triglyceride levels at final visit compared with first visit also increased significantly $(\mathrm{p}=0.04)$. A total of $186(56.4 \%)$ patients had drugrelated problems at first visit and 31 (9.4\%) patients at two-month visit.

Conclusion: The implementation of a patient-centered weight management model had a positive impact on the improvement of anthropometric, clinical and therapeutic parameters.

Keywords: community pharmacy services, weight management, medication review, drugrelated problem, patient-centered program

\section{Introduction}

The role of the pharmacist has traditionally centered on the provision of pharmacotherapeutic counselling, the evaluation of treatments and the prevention of adverse effects. ${ }^{1,2}$ However, given increasing demands on primary and emergency services and an aging population together with the higher prevalence of chronic diseases, the pharmacist's position has had to change towards a patient-centered model. Community pharmacists are particularly well positioned to provide these "pharmaceutical services" 3,4 which include both the management of medicines and clinical attention.

As a result, community pharmacists have developed new care models to offer a wide range of clinical services that include chronic disease management, disease
Correspondence: Blanca Lumbreras Department of Public Health, History of Science and Gynecology, Miguel Hernández University, CIBER in Epidemiology and Public Health, Road Alicante-Valencia km 8I, Sant Joan d'Alacant, Alicante 03550, Spain Tel +34965919510

Email blumbreras@umh.es
Patient Preference and Adherence 2020:|4 |50|-|5|| 
prevention, transition-of-care coordination, and other pertinent disease-monitoring and management interventions. ${ }^{5}$ In addition, given the financial and negative health consequences of inappropriate medication therapy, ${ }^{6}$ the role of pharmacists in optimizing medication use should be central to this new patient-centered model. ${ }^{7}$

Pharmacists are, therefore, becoming involved in different primary care-delivery models such as patientcentered medical homes ${ }^{8}$ in which each patient (or group of patients) is assigned to an interdisciplinary team and their care is coordinated across the different health care services. Pharmacists are also collaborating in interprofessional health care teams by contributing to a safe, effective and optimal medication use ${ }^{9}$ or by providing consultation services. ${ }^{10}$ They also lead patient care interventions focused on impactful outcomes (known as pharmacist-led intervention). ${ }^{11}$ Several studies have shown positive effects of pharmacist-led interventions in patients with chronic diseases. ${ }^{12}$ A previous systematic review evaluated the effect of pharmacist-led interventions in diabetes (types 1 and 2). ${ }^{13}$ Of the seven reviewed papers, six showed positive results which included interventions such as patient education, medication management and lifestyle changes. Other pharmacist-led interventions have been implemented in the management of gastroesophageal reflux disease to help patients to verify their diagnosis, referring them to a doctor when necessary and recommending treatment including medication, diet, and lifestyle advice. ${ }^{14}$ Another review showed how community pharmacist-led interventions could improve patients' adherence to medications and hence, contribute to improving blood pressure control, cholesterol management and asthma control. The most effective interventions were a combination of patient education, simplification of treatment regimens, communication between patients and their health care professionals, patient follow-up and monitoring. ${ }^{15}$

In this study, we want to evaluate the effect of a pharmacist-led intervention in the management of obesity and overweight. In this model, the role of the pharmacist was to provide education, counselling and advice on medication management to patients and patient education on healthy lifestyle promotion (including diet and physical activity). Obesity has reached pandemic levels with more than 1.4 billion adults affected worldwide and its prevalence is increasing. ${ }^{16}$ A recent scoping review of research articles ${ }^{17}$ showed that community pharmacists have an important role in the prevention and management of overweight and obesity. A pilot study in Australia developed and evaluated a pharmacist-delivered, non-productcentered weight management service for community pharmacies. The main outcomes were changes in weight, BMI and waist circumference at three months. The intervention was based on diet, physical activity and changes in behavior, and patients showed a significant mean change in all the parameters evaluated. ${ }^{18} \mathrm{~A}$ retrospective analysis of data collected by pharmacies as part of a weight management program was carried out in the UK. Pharmacists included patients with a BMI of $30 \mathrm{~kg} / \mathrm{m} 2$ or more and at least one risk factor for coronary heart disease, and motivated them to change their behavior. This study also showed reductions in weight and waist circumference. ${ }^{19}$ Nevertheless, community pharmacist services in weight management have until now focused only on weight loss and/or cardiovascular risk improvement but they did not take patients' concomitant health problems and medication management into consideration.

Although in Spain several interventions to reduce overweight have been implemented in the community pharmacies, there are no formal evaluations of their effects on patients' health. However, several interventions in weight management have been evaluated in the primary care setting. PREDIMED-Plus, for example, is a randomized controlled trial designed to analyze the effect of an intensive lifestyle intervention on cardiovascular risk factors associated with overweight and obesity, morbidity and mortality. The intervention, based on an energy-restricted Mediterranean diet, physical activity promotion and behavioral support, has shown significant results. ${ }^{20}$ Another randomized clinical trial evaluated whether a motivational intervention, together with current clinical practice, was more efficient than a traditional one in the treatment of overweight and obesity. Patients in the interventional group showed statistically significant weight reduction and improvements in biochemical markers. $^{21}$

In light of this, the evaluation of an intervention in weight management together with an optimization of the medication in community pharmacies needed to be developed. The results of such a study will demonstrate the role of the community pharmacy as a valuable actor in chronic disease control within the health system.

The aim of this study was to evaluate the provision of a professional pharmaceutical patient-centered model in a weight management program and optimization of the medication in a Spanish community pharmacy. 


\section{Patients and Methods Design and Setting}

To evaluate the provision of pharmaceutical services in a weight management program, we carried out a pilot test single-group intervention study in a community pharmacy, in Barcelona, Spain (2015-2018). Spain has a universal social security system, available to all citizens. However, community pharmacies are privately owned. There are geographic and population standards for the establishment of new pharmacies, resulting in an average of 1 pharmacy per 2000 residents.

\section{Patient Selection}

The recruitment started in January 2015 until the required sample size was achieved (last patient entered 13th November 2017). According to previous studies, ${ }^{19}$ a community pharmacy weight reduction program achieved a weight difference of $-3.07 \mathrm{~kg}$ after three months and $-4.59 \mathrm{~kg}$ after 6 months. Taking these values into account, with a power of $80 \%$ and a confidence level of $95 \%$, we needed to include a total of 280 patients. We increased this number by $15 \%$ because of loss to followup.

A pharmacist specialized in nutrition selected the patients and carried out the interventions. He was one of the contributors to the Spanish Society of Community Pharmacy Recommendations ${ }^{22}$ which were applied in the intervention. The pharmacist identified patients older than 18 years old with obesity-related comorbidities, based on their prescribed medication, and determined their willingness to participate in the program. Other strategies included recruiting patients who purchased weight-loss products or who enquired about weight-loss services. Pregnant women and patients with sudden weight gain or loss or severe uncontrolled diseases were considered not eligible. Informed consent was obtained by patients who met inclusion criteria once the pharmacist had explained the structure and objectives of the service.

The pharmacist collected the patient's contact details and set an appointment at the patient's convenience for the baseline visit. He established the second visit two months after the baseline visit. The final visit was established by the pharmacist according to patients' health status. However, it was never longer than 12 months after the baseline visit. Given that most of the patients included in the study received chronic medication, the pharmacist established the two-month and final visits in accordance with their medication collection date. This strategy limited the loss of follow-up.

\section{Interventions}

All the patients included in the program had at least three visits: 1) baseline visit, 2) two-month visit and 3) final visit. Each visit consisted of face-to-face interviews with the pharmacist in charge of the service, with a mean duration of 60 minutes. Patients could organize additional visits with the pharmacist by e-mail, telephone and/or WhatsApp if necessary.

The objectives of this program were: 1) To reduce body fat and maintain weight loss; 2) To decrease metabolic and cardiovascular risk factors; 3 ) To detect, solve and/or improve the control of related minor ailments, and 4) To conduct a medication review aimed at the detection and resolution of Drug-Related Problems (DRP) and Negative Clinical results (NCR).

To perform the interventions, the pharmacist followed the Spanish Society of Community Pharmacy recommendations. ${ }^{22}$ This guide aims to support the community pharmacist in monitoring overweight and obesity in people over 18 years of age with a BMI between 25 and 40 $\mathrm{Kg} / \mathrm{m} 2$, with or without risk factors associated, and also in those whose BMI is less than $25 \mathrm{Kg} / \mathrm{m} 2$, but with some risk factors. The guide is based on the Ministry of Health Consensus on Pharmaceutical Care $(2001)^{23}$ and on the Pharmaceutical Care Forum Consensus Document (2008). ${ }^{24}$ According to these recommendations, interventions were based on the patient's BMI. In patients with BMI $\geq 30$, their physicians were informed before the patient inclusion in the program. This intervention follows a pyramid-shaped representation which indicates a progressive increase in the complexity of the interventions as the patient's BMI increases, together with the higher prevalence of risk factors and comorbidities. Interventions involved the following areas: diet, physical exercise and medication review (Figure 1). In each visit, the patients received a written description of the diet to be followed and a description of healthy habits applied to each particular patient.

\section{Diet}

Dietary interventions consisted of two stages. The first consisted of advice on healthy habits and a list of recommended food, customized according to the physiological characteristics and associated pathologies of the patient. The second stage consisted of adapting the 


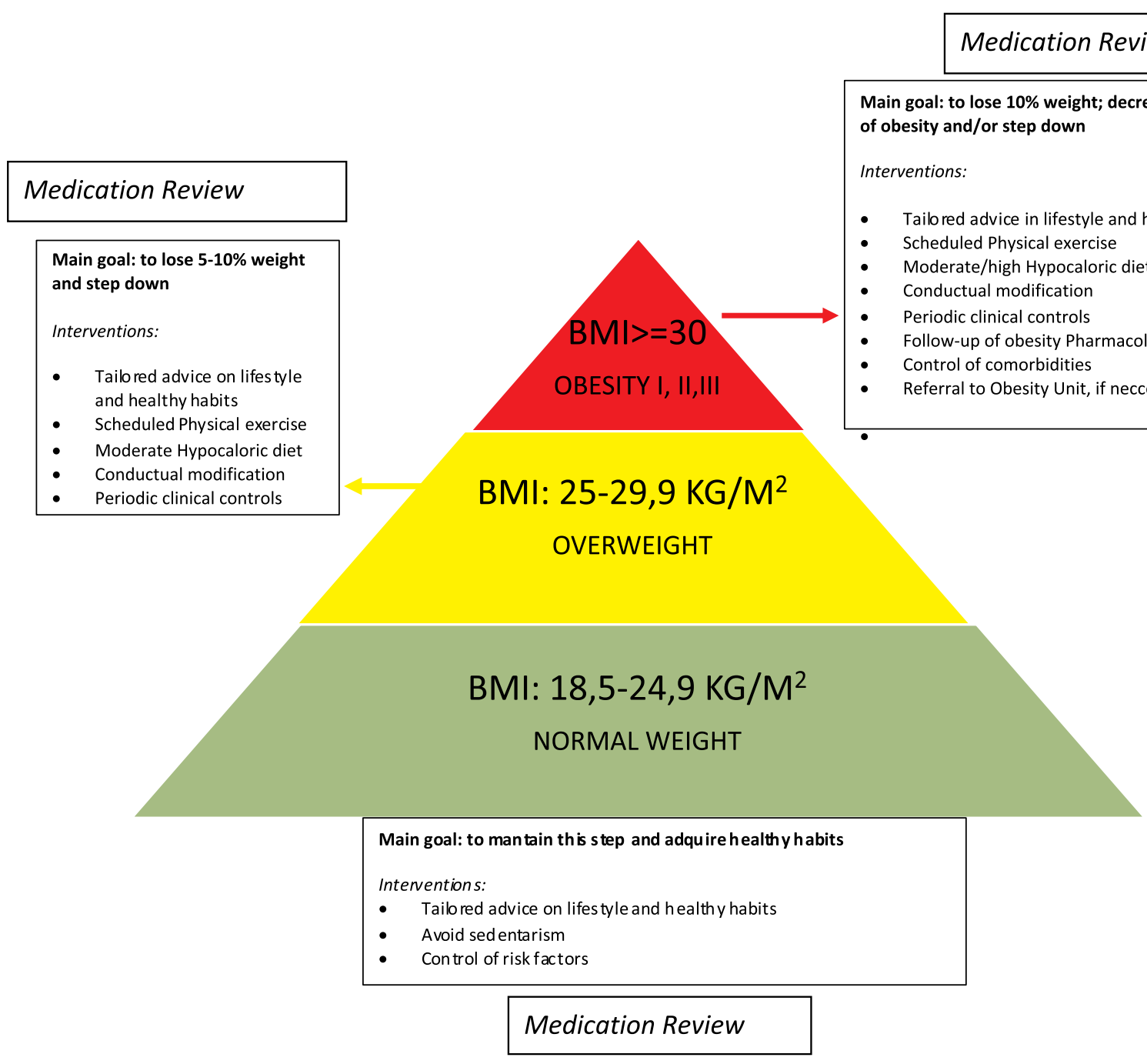

Figure I Pharmacist's interventions according to the patient's BMI. ${ }^{10}$

patient's calorific needs to his lifestyle, and preferences taking their comorbidities and/or risk factors into consideration.

\section{Physical Exercise}

The main objectives regarding physical exercise were to motivate the patient to reduce sedentary lifestyle by progressively increasing the intensity and duration of caloric burning physical activity.

\section{Medication Review}

The pharmacist interviewed all patients about their health problems and their use of medicines. A review and assessment of this information was undertaken to identify any Negative Clinical Results associated with medication (NCR) and their possible causes (DrugRelated Problem, DRP). DRP and NCR were classified according to Spanish Forum Community Pharmacy classification. ${ }^{25}$ In this classification, DRP are defined as process elements increasing medication user's risk of suffering from negative outcomes related to medicines and NCR as negative patient health outcomes that are not in accordance with the objectives of the pharmacotherapy, possibly associated with the use of medicines. In addition, if the patient was following any treatment for overweight or obesity, which is common in patients with BMI over 30, they carried out an evaluation of its effectiveness and safety. Pharmacist interventions consisted in the formulation of recommendations to patients and/or physicians, and referrals if necessary, and advice regarding medicine's optimization. In the case of detecting any untreated minor ailment, the pharmacist applied the methodology for the Pharmaceutical Indication Service. ${ }^{25}$ 


\section{Data Collection}

In the baseline visit, the pharmacist conducted an in-depth patient interview using a structured questionnaire, to obtain the necessary minimum basic data set. Information collected included: 1) sociodemographic and anthropometric variables: age, sex, height, weight, body mass index (BMI) and waist circumference; 2) Dietary history and lifestyle habits, including food intake during the previous 24 hours; 3) Biochemical measurements: Cholesterol, LDL-cholesterol, Triglycerides, Blood glucose and Glycosylated hemoglobin. These determinations were carried out in the community pharmacy using Reflotron Plus biochemical analyzer (Roche Diagnostics, Switzerland); 4) presence of minor ailments, such as digestive (constipation, reflux, flatulence or dyspepsia), mood disorders or insomnia; and 5) Other clinical and therapeutic data needed for the medication review: data regarding prescribed and over the counter (OTC) medicines, and patient's knowledge about their treatment. The pharmacist also assessed treatment adherence using the Morisky-Green test. Goal settings and Dietary and Pharmacotherapy action plans were provided at the end of the baseline visit. Body weight $(\mathrm{kg})$ was measured using an Omron Karada ScanSeca digital scale. Height $(\mathrm{cm})$ was measured using a Charder HM200P Portstad portable stadiometer. Waist Circumference $(\mathrm{cm})$ was obtained using a tape measure, mid-way between the lower rib margin and the iliac crest. Two seated blood pressure (mmHg) measurements were taken 5 min apart using an Omron M6 Confort IT digital blood pressure monitor. The mean of two measurements for waist circumference and blood pressure were recorded.

The followed-up visit used to take place when the patient attended the pharmacy to collect their prescribed medicines, previous appointment with the pharmacist. In the two-month visit, patients were interviewed again with the same procedure as in the baseline visit, in order to evaluate progresses and discuss barriers to change. The results of the different action plans were re-assessed, by evaluating the impact of the interventions and identifying unsolved problems or remaining issues. The pharmacist registered anthropometric (weight, BMI and waist circumference) and biochemical measurements (cholesterol, LDL-cholesterol, triglyceride, blood glucose and glycosylated hemoglobin levels) and provided tailored advice regarding diet and physical activity. At final visit, the pharmacist carried out a final clinical measurement, following the same procedure as in previous visits (interview and anthropometric and biochemical measurements) and discussed how to maintain weight loss and healthy habits.

\section{Statistical Analysis}

Patients were individualized by means of dissociated, nonidentifiable, nonsense codes for any other information system and that did not allow the identification of individual patients or their crossing with other databases. The database did not contain any data that allowed the identification of patients and the research team did not have neither from these databases nor from other sources patient identification information.

Statistical precision was determined through the calculation of $95 \%$ confidence intervals using the appropriate method according to the type of measurement and the available data. All analyses were carried out with the statistical program $\mathrm{R}$.

A descriptive analysis was made of all the study variables, calculating the mean, standard deviation (variables were tested for normality using the Shapiro-Wilk tests; and parametric tests were performed when data did not violate the normality assumptions), total frequency and relative frequency of each category; $95 \%$ confidence intervals were calculated for the proportions.

Mean changes of primary outcome measures and $95 \%$ confidence intervals (CI) were determined. Repeated measures analysis of variance was used to assess changes. In categorical variables, we applied the Chi-squared test to determine any change in the 3 periods of study.

\section{Results}

A total of 330 patients were included in the weight management program in the community pharmacy at baseline and we had no losses to follow-up. Mean follow-up was 8.2 months (sd 2.3) which included at least two visits per patient after the baseline visit: mean period between the two-month visit and the final visit was 5.3 months (sd 2.9).

Mean age was 51.3 (sd 15.3) years old and 264 $(80.0 \%)$ of the patients were women. The majority were Spanish $(307,93.0 \%)$ and $175(53.0 \%)$ never-smokers.

\section{Evaluation of Patients' Clinical Variables During Follow-Up \\ Anthropometric Variables}

There was a statistically significant reduction in anthropometric measures (weight, BMI, and waist circumference) at final visit compared with baseline visit $(\mathrm{p}<0.001)$ 
(Table 1). Three hundred and twenty-two patients $(92,3 \%)$ have lost weight and 7 patients $(2,0 \%)$ have gained weight at final visit compared with baseline visit.

The number of patients with obesity (including class I, II and III) at baseline visit was 166 (50.3\%) and 113 (34.2\%) on the final visit. The number of patients with normal weight $(35,10.6 \%)$ rose to $75(22.7 \%)$ on the last visit $(\mathrm{p}<0.001)$.

During the follow-up period (final visit-baseline visit), the BMI mean difference was -2.1 (sd. 1.8) (maximum $-3.2)$ and $322(92.3 \%)$ patients showed a reduction in BMI. Mean weight difference between final and baseline visit was $-5.4 \mathrm{Kg}(95 \% \mathrm{CI}-7.4,-2.6)$ (maximum $-32.0 \mathrm{~kg})$ and $-3,65 \mathrm{~kg}(95 \% \mathrm{CI}-5.0,-2.0)$ between twomonth and baseline visit. In addition, 125 (37.9\%) patients showed a weight reduction higher than $5 \%$ on final visit compared with baseline visit. Mean waist circumference difference was $-4.1 \mathrm{~cm}(\mathrm{sd} .6 .1 \mathrm{~cm})$ during the whole follow-up period.

\section{Biochemical Variables}

Cholesterol and LDL-cholesterol levels also showed a significant reduction on two-month visit and final visit compared with baseline visit: of 33 people with uncontrolled cholesterol level at baseline visit, 27 (81.8\%) showed a normal level on the final visit $(\mathrm{p}<0.001)$. At baseline visit, 291 (88.2\%) had normal LDL-cholesterol levels and this percentage rose in the final visit (313, $94.8 \%)(p=0.001)$. Patients with uncontrolled triglyceride showed a significant reduction on final visit compared with baseline visit $(\mathrm{p}=0.004)$.

\section{Evaluation of Other Patients' Health Problems During Follow-Up}

At baseline, 226 patients $(68,5 \%)$ had at least one minor ailment: $30.6 \%$ of patients had mood disorders, $19.0 \%$ insomnia and $18.8 \%$ digestive disorders, which were untreated in $42.6 \%, 27.0 \%$ and $35.5 \%$ of cases, respectively (Table 2).

There was a significant difference in the prevalence of mood and digestive disorders at final visit compared with baseline visit. Of the 101 (30.6\%) patients with mood disorders and the $62(18.8 \%)$ patients with digestive disorders at baseline, $74(22.5 \%) 69$ of them controlled with treatment $(21.0 \%)$ and 41 of them controlled with $(12.4 \%)$ respectively, reported them at final visit $(\mathrm{p}=0.017$ and $\mathrm{p}=0.024$, respectively).

\section{Medication Management During Follow-Up}

At baseline visit, $204(61.8 \%)$ patients were treated with over 3 medications (mean 3.7, sd 2.6) and this percentage increased at final visit $(240,72.7 \%)$. Adherence to treatment increased during the follow-up period: 131, 64.5\% patients at baseline visit and $217,90.4 \%$ at final visit (Table 3).

A total of $186(56.4 \%)$ patients had DRP at first visit (308 DRP) and 31 (9.4\%) patients at two-month visit (27 DRP). No medication-related problems were detected at final visit (Table 4). The most commonly found DRP belongs to the category "insufficiently treated health problem" (188, 61.2\%) followed by "dose inadequate, pattern and/or duration" $(89,28.8 \%)$.

Of the 308 NCR associated with medication detected at baseline visit, 169 (54.9\%) belong to the category "necessity", $119(38.6 \%)$ to "effectiveness" and $20(6.5 \%)$ to "safety". At two-month visit, 27 negative clinical results associated with medication were detected.

At baseline visit, the main intervention in patients with NCR associated with medication was a pharmacist's recommendation aimed at the patient $(194,63.0 \%)$ followed by pharmacist's recommendation aimed at physician (64, $20.8 \%)$ and both of them $(50,16.2 \%)$. At two-month visit, 252 of the NCR associated with medication detected at baseline were solved $(81.8 \%)$.

\section{Discussion}

This study describes the evaluation of a patient-centered model to control overweight, obesity and other concomitant health problems in a Spanish community pharmacy. In this model, patients achieved a significant reduction in weight and waist circumference after two months of follow-up. Patients' cholesterol, LDLcholesterol and triglyceride levels also showed a significant reduction. The pharmaceutical intervention detected 308 negative clinical results associated with medication and the number of patients with mood and digestive minor ailments significantly decreased during the follow-up period.

According to previous evidence, a reduction of $5 \%$ from initial weight in people with overweight and obesity is sufficient to gain some health benefits. ${ }^{26}$ In our study, nearly $20 \%$ of the patients achieved this weight reduction at two-month visit and nearly $40 \%$ at the end of follow-up. This proportion was similar to other weight management programs in the community pharmacy. ${ }^{17}$ A previous pilot 
Table I Evaluation of Patients' Clinical Variables During the Follow-Up

\begin{tabular}{|c|c|c|c|c|c|c|}
\hline Variable (n, \%) & $\begin{array}{l}\text { Baseline } \\
\text { Visit }\end{array}$ & $\begin{array}{l}\text { 2-Month } \\
\text { Visit }\end{array}$ & Final Visit & $\begin{array}{l}\text { P-value } \\
\text { (2-Month Visit- } \\
\text { Baseline Visit) }\end{array}$ & $\begin{array}{l}\text { P-value (Final } \\
\text { Visit-2-Month } \\
\text { Visit) }\end{array}$ & $\begin{array}{l}\text { P-value (Final } \\
\text { Visit-Baseline } \\
\text { Visit) }\end{array}$ \\
\hline \multicolumn{7}{|l|}{ Anthropometric variables } \\
\hline $\begin{array}{l}\text { - } \text { BMI } \\
\text { - Normal weight (I8-24.9) } \\
\text { - Overweight class I (25-26.9) } \\
\text { - Overweight class II (27-29.9) } \\
\text { - Obesity class I (30-34.9) } \\
\text { - Obesity class II (35-39.9) } \\
\text { - Obesity class III (>40) }\end{array}$ & $\begin{array}{l}35(10.6) \\
51(15.5) \\
78(23.6) \\
93(28.2) \\
47(14.2) \\
26(7.9)\end{array}$ & $\begin{array}{l}59(17.9) \\
70(21.2) \\
71(21.5) \\
71(21.5) \\
41(12.4) \\
18(5.5)\end{array}$ & $\begin{array}{l}75(22.7) \\
76(23.0) \\
66(20.0) \\
64(19.4) \\
35(10.6) \\
14(4.2)\end{array}$ & $<0.001$ & $<0.001$ & $<0.001$ \\
\hline $\begin{array}{l}\text { Weight }(\mathrm{kg}) \text { (mean. } \mathrm{sd}) \\
\text { Waist circumference }(\mathrm{cm}) \text { (mean. sd) }\end{array}$ & $\begin{array}{l}81.6(17.9) \\
103.9(14.1)\end{array}$ & $\begin{array}{l}77.9(17.3) \\
101.6(13.9)\end{array}$ & $\begin{array}{l}76.2(16.9) \\
100.2(13.7)\end{array}$ & $\begin{array}{l}0.014 \\
0.026\end{array}$ & $\begin{array}{l}0.190 \\
0.165\end{array}$ & $\begin{array}{l}<0.001 \\
<0.001\end{array}$ \\
\hline \multicolumn{7}{|l|}{ Biochemical variables } \\
\hline $\begin{array}{l}\text { Cholesterol } \\
\text { - Normal } \\
\text { o Without treatment } \\
\text { o With treatment } \\
\text { - Uncontrolled } \\
\text { - Not available }\end{array}$ & $\begin{array}{l}297(90.0) \\
264 \\
33 \\
33(10.0)\end{array}$ & $\begin{array}{l}31 \mid(94.2) \\
280 \\
31 \\
18(5.5) \\
1(0.3)\end{array}$ & $\begin{array}{l}324(97.2) \\
299 \\
25 \\
6(1.8)\end{array}$ & 0.029 & 0.012 & $<0.001$ \\
\hline $\begin{array}{l}\text { LDL cholesterol } \\
\text { - Normal } \\
\text { o Without treatment } \\
\text { o With treatment } \\
\text { - Uncontrolled } \\
\text { - Not available }\end{array}$ & $\begin{array}{l}291(88.2) \\
264 \\
27 \\
26(7.9) \\
13(3.9)\end{array}$ & $\begin{array}{l}305(92.4) \\
276 \\
29 \\
10(3.0) \\
15(4.5)\end{array}$ & $\begin{array}{l}313(94.8) \\
289 \\
24 \\
8(2.4) \\
9(2.7)\end{array}$ & 0.006 & 0.604 & 0.001 \\
\hline $\begin{array}{l}\text { Triglycerides } \\
\text { - Normal } \\
\text { o Without treatment } \\
\text { o With treatment } \\
\text { - Uncontrolled } \\
\text { - Not available }\end{array}$ & $\begin{array}{l}317(96.1) \\
313 \\
4 \\
13(3.9)\end{array}$ & $\begin{array}{l}323(97.9) \\
319 \\
4 \\
6(1.8) \\
1(0.3)\end{array}$ & $\begin{array}{l}327(99.1) \\
325 \\
2 \\
2(0.6) \\
1(0.3)\end{array}$ & 0.105 & 0.155 & 0.004 \\
\hline $\begin{array}{l}\text { Blood glucose } \\
\text { - Normal } \\
\text { ○ Without treatment } \\
\text { ○ With treatment } \\
\text { - Uncontrolled }\end{array}$ & $\begin{array}{l}316(95.8) \\
306 \\
10 \\
14(4.2)\end{array}$ & $\begin{array}{l}320(97.0) \\
311 \\
9 \\
10(3.0)\end{array}$ & $\begin{array}{l}322(97.6) \\
314 \\
8 \\
8(2.4)\end{array}$ & 0.401 & 0.633 & 0.193 \\
\hline $\begin{array}{l}\text { Glycosylated hemoglobin } \\
\text { - Normal } \\
\text { o Without treatment } \\
\text { o With treatment } \\
\text { - Uncontrolled } \\
\text { - Not available }\end{array}$ & $\begin{array}{l}315(95.5) \\
306 \\
9 \\
14(4.2) \\
1(0.3)\end{array}$ & $\begin{array}{l}317(96.1) \\
309 \\
8 \\
12(3.6) \\
1(0.3)\end{array}$ & $\begin{array}{l}318(96.4) \\
310 \\
8 \\
12(3.6)\end{array}$ & 0.689 & 0.994 & 0.683 \\
\hline
\end{tabular}

study in Australian community pharmacies showed that $32 \%$ of participants achieved a weight loss of $5 \%$ after three months of follow-up. ${ }^{18}$ In another study, carried out in community pharmacies in the UK, around a quarter of the patients included in the intervention achieved 5\% reduction in body weight at 3 months. ${ }^{19}$

According to a systematic review on studies carried out in community pharmacies, ${ }^{12}$ the size of mean change in 
Table 2 Evaluation of Other Patients' Health Problems During the Follow-Up

\begin{tabular}{|c|c|c|c|c|c|c|}
\hline Health Problem & $\begin{array}{l}\text { Baseline } \\
\text { Visit } \\
(\mathbf{N}=330)\end{array}$ & $\begin{array}{l}\text { 2-Month } \\
\text { Visit } \\
(\mathrm{N}=330)\end{array}$ & $\begin{array}{l}\text { Final } \\
\text { Visit } \\
(N=330)\end{array}$ & $\begin{array}{l}\text { P-value } \\
\text { (2-Month Visit- } \\
\text { Baseline Visit) }\end{array}$ & $\begin{array}{l}\text { P-value (Final } \\
\text { Visit-2-Month } \\
\text { Visit) }\end{array}$ & $\begin{array}{l}\text { P-value (Final } \\
\text { Visit-Baseline } \\
\text { Visit) }\end{array}$ \\
\hline $\begin{array}{l}\text { Mood disorders } \\
\text { - No } \\
\text { - Yes } \\
\text { ○ No treatment } \\
\text { ○ Controlled with effective treatment } \\
\text { ○ Ineffective treatment }\end{array}$ & $\begin{array}{l}229(69.4) \\
101(30.6) \\
44(13.3) \\
32(9.7) \\
25(7.6)\end{array}$ & $\begin{array}{l}239(72.4) \\
91(27.6) \\
2(0.6) \\
83(25.2) \\
6(1.8)\end{array}$ & $\begin{array}{l}256(77.5) \\
74(22.5) \\
1(0.3) \\
69(21.0) \\
4(1.2)\end{array}$ & 0.391 & 0.127 & 0.017 \\
\hline $\begin{array}{l}\text { Insomnia } \\
\text { - No } \\
\text { - Yes } \\
\text { ○ No treatment } \\
\text { ○ Controlled with effective treatment } \\
\text { ○ Ineffective treatment }\end{array}$ & $\begin{array}{l}267(81.0) \\
63(19.0) \\
17(5.1) \\
33(10.0) \\
13(3.9)\end{array}$ & $\begin{array}{l}267(81.0) \\
63(19.0) \\
3(0.9) \\
53(16.1) \\
7(2.1)\end{array}$ & $\begin{array}{l}280(84.9) \\
50(15.1) \\
0(0) \\
45(13.6) \\
5(1.5)\end{array}$ & - & 0.179 & 0.179 \\
\hline $\begin{array}{l}\text { Digestive disorders } \\
\text { - No } \\
\text { - Yes } \\
\text { ○ No treatment } \\
\text { ○ Controlled with effective treatment } \\
\text { ○ Ineffective treatment }\end{array}$ & $\begin{array}{l}268(81.2) \\
62(18.8) \\
22(6.7) \\
39(11.8) \\
1(0.3)\end{array}$ & $\begin{array}{l}282(85.5) \\
48(14.5) \\
4(1.2) \\
44(13.3)\end{array}$ & $\begin{array}{l}289(87.6) \\
4 I(12.4) \\
4 I(12.4)\end{array}$ & 0.144 & 0.452 & 0.024 \\
\hline
\end{tabular}

Table 3 Description of the Medication Use in the Patients During the Followed-Up

\begin{tabular}{|c|c|c|c|c|c|c|}
\hline \multirow[t]{2}{*}{ Variables } & \multicolumn{2}{|c|}{$\begin{array}{l}\text { Baseline } \\
\text { Visit }\end{array}$} & \multicolumn{2}{|c|}{$\begin{array}{l}\text { 2-Month } \\
\text { Visit }\end{array}$} & \multicolumn{2}{|c|}{$\begin{array}{l}\text { Final } \\
\text { Visit }\end{array}$} \\
\hline & $\mathbf{N}$ & $\%$ & $\mathbf{N}$ & $\%$ & $\mathbf{N}$ & $\%$ \\
\hline $\begin{array}{l}\text { People with at least I } \\
\text { medication }\end{array}$ & 204 & 61.8 & 231 & $70.0 \%$ & 240 & 72.7 \\
\hline $\begin{array}{l}\text { Medications per person } \\
\text { (mean. sd)* }\end{array}$ & 3.7 & 2.6 & 3.6 & 2.7 & 3.6 & 2.8 \\
\hline Adherence to treatment & & & & & & \\
\hline - Yes & $|3|$ & 64.5 & 212 & 91.8 & 217 & 90.4 \\
\hline - No & 72 & 35.5 & 13 & 5.6 & 9 & 3.8 \\
\hline - No Data & I & 0.5 & 6 & 2.6 & 14 & 5.8 \\
\hline
\end{tabular}

Note: *In those people with at least I medication.

weight in our study was similar to that in previous studies $(-3,65 \mathrm{~kg}, 95 \% \mathrm{CI}-5.0,-2.0)$ at two-month visit and higher $(-5.4 \mathrm{~kg}, 95 \% \mathrm{CI}-7.4,-2.6)$ at final visit compared with baseline visit. In the Australian study, where $65 \%$ of the participants completed the program, mean change in weight was $-3.5 \mathrm{~kg}(95 \% \mathrm{CI}-4.8,-2.2)$ after three months of follow-up. ${ }^{18}$ In the study reporting UK pharmacy-based weight management intervention, the size of mean change in weight was $-3.07 \mathrm{~kg}$, but there was a high loss to follow-up (61\% at 3 months). ${ }^{19}$ Patients in our study also showed a significant weight reduction during a mean follow-up of 8 months while in previous studies a long-term ( $>6$ months) weight loss maintenance was not achieved. ${ }^{14,15}$

In Spain, several clinical trials at the primary care setting have also focused on weight management. For instance, in the Predimed-Plus study, weight loss $>5 \%$ occurred in $34 \%$ of participants and a mean difference of $-2.5 \mathrm{~kg}(95 \% \mathrm{CI}-3.1$ to -1.9$)$ was shown after 12 months of follow-up. ${ }^{27}$ In another study in primary care setting where the intervention was limited to a motivational intervention, a $5 \%$ reduction in weight was achieved by $22.6 \%$ of patients at 12 months of follow-up (no statistically significant differences with the control group) and nearly $50 \%$ of patients were lost to follow-up. ${ }^{21}$

A possible explanation for these differences with previous studies carried out in community pharmacies or in Spanish primary care centers could be that we had no losses to follow-up while in these previous studies the average participant dropout rate ranged from $8.3 \%$ to $79 \%$. The high retention of patients in our study could be due to this ongoing follow-up taking place when patients on regular prescription medicines collected them in the community pharmacy. Community pharmacists are, therefore, ideally 
Table 4 Description of the Drug-Related Problems and Negative Clinical Adverse Drug Reactions Detected in the Patients at Baseline and During the Followed-Up

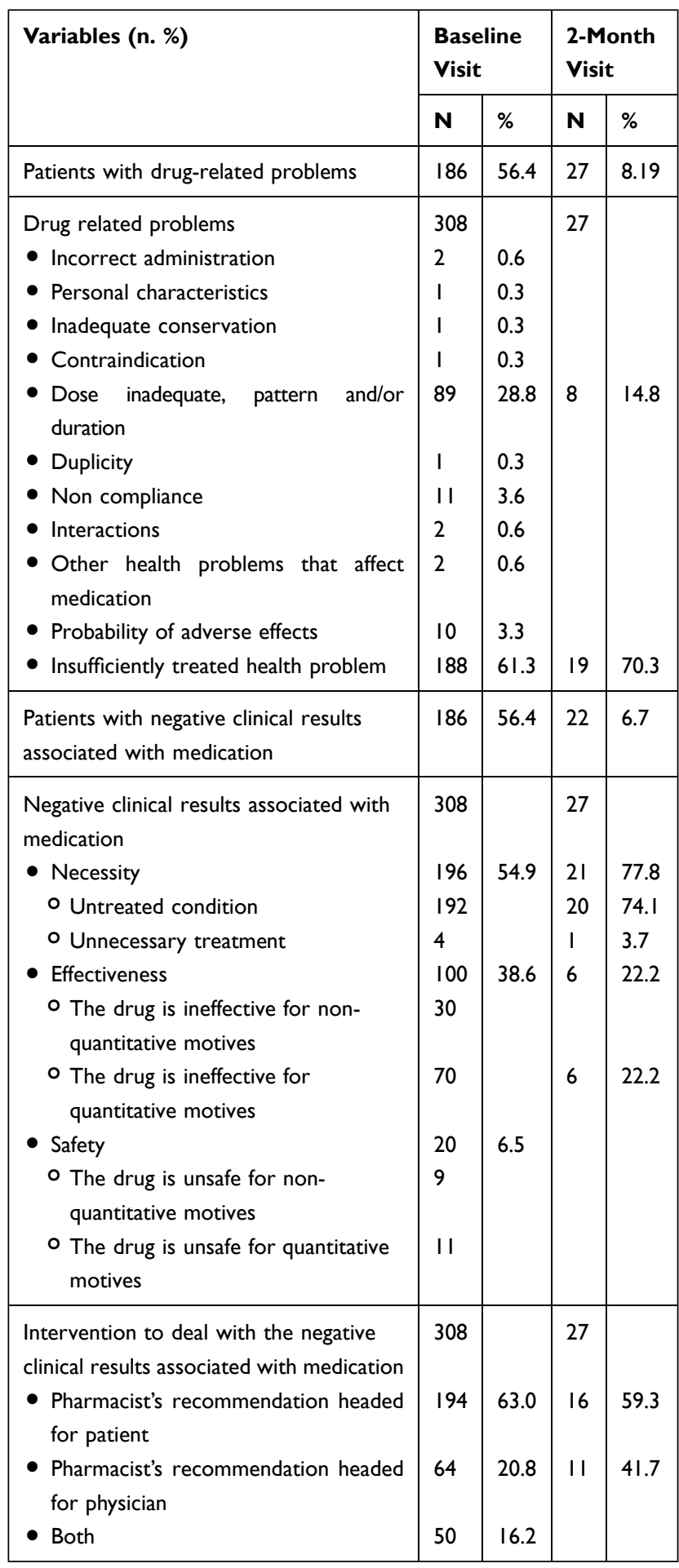

placed to provide weight management advice and, according to previous evidence, a relationship of trust with the pharmacist could explain the high adherence rate. ${ }^{28}$

Cholesterol, LDL-cholesterol and triglyceride levels significantly decreased during the follow-up period.
Previous research has also reported that modest weight loss (3-5 kg) through a low-carbohydrate diet after 6 months of intervention can improve other markers related with cardiovascular disease. ${ }^{16}$ We did not observe changes in other parameters such as blood glucose or hemoglobin glycosylate because they take longer to be reflected.

According to a previous scoping review, ${ }^{17}$ weight management programs carried out in community pharmacies have until now been centered on behavioral counselling given to the patients. However, none of them have included in the intervention the evaluation of other chronic diseases and optimization of medication. In this study, we wanted to take advantage of the pharmacist's role as an expert in medication, to review patients' prescriptions. The number of negative clinical results associated with medication at baseline visit was lower than those shown in previous literature. ${ }^{29,30}$ In our study, a total of 186 (56.4\%) patients had drug-related problems (DRP) at first visit. In contrast, in a previous study in German pharmacies, $95 \%$ of the 912 patients evaluated had at least one DRP or information need. ${ }^{29}$ Another study in the Netherlands ${ }^{30}$ evaluated the effect of Comprehensive Medication Review (CMR) in community pharmacies and pharmacists detected on average 2.9 (sd 2.1) DRPs per CMR. The lower rates of DRP in our study (but still, relevant), could be explained by the characteristics of our patients who wanted to participate in an interventional study to improve their health status and were therefore more aware of their health problems and medication than the general population.

The most frequently found negative clinical result belongs to the category of necessity (untreated condition) and the second most frequent finding belongs to the category of effectiveness (the drug is ineffective for quantitative and for non-quantitative reasons). In fact, a significant percentage of patients with some minor ailments such as mood and digestive disorders or insomnia either did not have a prescribed treatment or the treatment was ineffective. These results are different from previous studies where the most frequent problem was related with the presence of adverse effects. ${ }^{31,32}$ However, patients in previous studies consumed on average more medications than those in our study and the probability of adverse effects was greater.

The evaluation of the negative results related with medication during the follow-up period indicates that community pharmacists can identify patients with these problems and solve many of them in the course of 
a medication review. The high prevalence of DRP found in our study justifies the integration of the medication review in a weight management program, as the pharmacist detected at least one opportunity for the improvement of pharmacotherapy in more than one of each two of the patients recruited.

Furthermore, this medication review resulted in a lower prevalence of patients with minor ailments such as mood or digestive disorders (constipation, reflux or flatulence). The first-line treatment of minor ailments usually includes advices about dietary and lifestyle modifications. ${ }^{33}$ The problem is that in most cases at the community pharmacy, these advices are given quickly when the drug is being dispensed and the impact of the intervention on patient's health is probably very low. Pharmacists use to be more comfortable providing lifestyle advices in conjunction with conversations about medicines. ${ }^{34}$ So, to provide a more individualized approach, these interventions should be implemented in the context of specific Pharmaceutical Services.

The main limitation of this study is the application of a single-group intervention study with repeated measures without control group that can limit the results. However, we wanted to evaluate the implementation of a global pharmaceutical service in daily clinical practice. In addition, given the potential efficacy of an intervention related with weight management and medication review to improve patients' health, we chose this design for ethical reasons. We showed the results from a single community pharmacy, and our findings might not be generalizable. Nevertheless, the sample characteristics were comparable with the reference population in other similar studies, including gender distribution. ${ }^{35}$

We used Pharmaceutical Care Forum in Community Pharmacy $^{25}$ classification to evaluate medication because it is validated for use in Spain. Very few studies have used this classification, and most of them were carried out in institutionalized people whose medication is more strictly controlled. Thus, the comparison with previous literature was limited.

We did not estimate the cost of pharmaceutical services and time spent with services. Further studies including economic aspects are needed in order to update the current model of pharmaceutical services.

\section{Conclusion}

This study demonstrates that the implementation of a patient-centered weight management model had a positive impact on the improvement of anthropometric, clinical and therapeutic parameters. In addition, the medication review allows detecting and resolving untreated conditions, resolve minor ailments, and improve the adherence to the treatments and other morbidity situations that interfere with the patient's quality of life. The community pharmacy, as a place where the patient usually goes to seek advice for weight-loss and/or to collect medication, is the most accessible healthcare point to provide weight and lifestyle management services, as well as to prevent, detect and resolve opportunities for improvement the quality of pharmacotherapy in these patients.

\section{Ethical and Consent}

Institutional Review Board approval for the study was obtained from General Hospital University Elda (RB PI2019/32). Informed consent was received from study participants and the guidelines outlined in the Declaration of Helsinki were followed.

\section{Acknowledgment}

We thank Jessica Gorlin for language editing.

\section{Disclosure}

The authors report no conflicts of interest in this work.

\section{References}

1. Bunting BA, Cranor CW. The asheville project: long-term clinical, humanistic, and economic outcomes of a community-based medication therapy management program for asthma. $J$ Am Pharm Assoc. 2006;46 (2):133-147. doi:10.1331/154434506776180658

2. Bosse N, Machado M, Mistry A. Efficacy of an over-the-counter intervention follow-up program in community pharmacies. $J \mathrm{Am}$ Pharm Assoc. 2012;52(4):535-540. doi:10.1331/JAPhA.2012.10093

3. Newman TV, Hernandez I, Keyser D, et al. Optimizing the role of community pharmacists in managing the health of populations: barriers, facilitators, and policy recommendations. J Manag Care Spec Pharm. 2019;25:995-1000. doi:10.18553/jmcp.2019.25.9.995

4. Moullin JC, Sabater-Hernández D, Fernandez-Llimos F, Benrimoj SI. Defining professional pharmacy services in community pharmacy. Res Social Adm Pharm. 2013;9(6):989-995. doi:10.1016/j.sapharm.20 13.02.005

5. Hemberg N, Huggins D, Michaels N, Moose J. Innovative community pharmacy practice models in North Carolina. $N C$ Med $J$. 2017;78:198-201. doi:10.18043/ncm.78.3.198

6. Watanabe JH, McInnis T, Hirsch JD. Cost of prescription drug-related morbidity and mortality. Ann Pharmacother. 2018;52:829-837. doi: $10.1177 / 1060028018765159$

7. Rosenbaum L, Shrank WH. Taking our medicine - improving adherence in the accountability era. $N$ Engl J Med. 2013;369:694-695. doi:10.1056/NEJMp1307084

8. Lewis NJ, Shimp LA, Rockafellow S, Tingen JM, Choe HM, Marcelino MA. The role of the pharmacist in patient-centered medical home practices: current perspectives. Integr Pharm Res Pract. 2014;3:29-38. doi:10.2147/IPRP.S62670 
9. Chisholm-Burns MA, Kim Lee J, Spivey CA, et al. US pharmacists' effect as team members on patient care: systematic review and metaanalyses. Med Care. 2010;48:923-933. doi:10.1097/MLR.0b013e3 $181 \mathrm{e} 57962$

10. Tan ECK, Stewart K, Elliott RA, George J. Pharmacist consultations in general practice clinics: the Pharmacists in Practice Study (PIPS) Res Social Adm Pharm. 2014;10(4):623-632. doi:10.1016/j.sapharm. 2013.08.005

11. Thomas R, Huntley AL, Mann M, et al. Pharmacist-led interventions to reduce unplanned admissions for older people: a systematic review and meta-analysis of randomised controlled trials. Age Ageing. 2014;43(2):174-187. doi:10.1093/ageing/aft169

12. Newman TV, San-Juan-Rodriguez A, Parekh N, et al. Impact of community pharmacist-led interventions in chronic disease management on clinical, utilization, and economic outcomes: an umbrella review. Res Social Adm Pharm. 2020;S1551-S7411:30553-30554.

13. Blenkinsopp A, Hassey A. Effectiveness and acceptability of community pharmacy-based interventions in type 2 diabetes: a critical review of intervention design, pharmacist and patient perspectives. Int J Pharm Pract. 2005;13(4):231-240. doi:10.1211/ijpp.13.4.0001

14. MacFarlane B. Management of gastroesophageal reflux disease in adults: a pharmacist's perspective. Integr Pharm Res Pract. 2018;7:41-52. doi:10.2147/IPRP.S142932

15. Milosavljevic A, Aspden T, Harrison J. Community pharmacist-led interventions and their impact on patients' medication adherence and other health outcomes: a systematic review. Int $J$ Pharm Pract. 2018;26(5):387-397. doi:10.1111/ijpp.12462

16. The Organisation for Economic Cooperation and Development (OECD). Obesity update. 2017. Available from: https://www oecd.org/health/health-systems/Obesity-Update-2017.pdf. Accessed October 1, 2019.

17. Rosenthal M, Ward LM, Teng J, Haines S. Weight management counselling among community pharmacists: a scoping review. Int J Pharm Pract. 2018;26(6):475-484. doi:10.1111/ijpp.12453

18. Um IS, Krass I, Armour C, Gill T, Chaar BB. Developing and testing evidence-based weight management in Australian pharmacies: a healthier life program. Int J Clin Pharm. 2015;37(5):822-833. doi:10.1007/s11096-015-0126-z

19. Boardman HF, Avery AJ. Effectiveness of a community pharmacy weight management programme. Int J Clin Pharm. 2014;36 (4):800-806. doi:10.1007/s11096-014-9964-3

20. Fuentes GC, Castañer O, Warnberg J, et al. Prospective association of physical activity and inflammatory biomarkers in older adults from the PREDIMED-plus study with overweight or obesity and metabolic syndrome. Clin Nutr. 2020;S0261-S5614:30038.

21. Rodriguez-Cristobal JJ, Alonso-Villaverde C, Panisello JM, et al. Effectiveness of a motivational intervention on overweight/obese patients in the primary healthcare: a cluster randomized trial. $B M C$ Fam Pract. 2017;18(1):74. doi:10.1186/s12875-017-0644-y

22. Ruiz I, Ferran J, Gómez- Martínez JC, Ruiz B, Cayuelas R, Murillo MD. Guía simplificada de intervención farmacéutica en normopeso con factores de riesgo, sobrepeso y obesidad. Farmaceuticos Comunitarios. 2009;1:124-129.
23. Ministry of Health Consensus on Pharmaceutical Care Madrid. 2001. Available from: https://www.mscbs.gob.es/profesionales/farmacia/ consenso/consenso.htm. Accessed January 1, 2020.

24. Pharmaceutical Care Forum. Consensus document. Madrid. 2008 Available from: https://www.portalfarma.com/inicio/serviciosprofesio nales//forofarmaciacomunitaria/Documents/ATFC_Guia\%20FORO. pdf. Accessed January 1, 2020.

25. Pharmaceutical Care Forum Community Pharmacy. Practical Guide to Pharmaceutical Care Services in Community. May 2010. Ed. Madrid: General Council of Official Pharmaceutical Associations. ISBN-13: 978-84-693-1717-4.

26. Blackburn G. Effect of degree of weight loss on health benefits. Obes Res. 1995;3(Suppl S2):211s-6s. doi:10.1002/j.1550-8528.1995.tb00466.x

27. Salas-Salvadó J, Díaz-López A, Ruiz-Canela M, et al. Effect of a lifestyle intervention program with energy-restricted mediterranean diet and exercise on weight loss and cardiovascular risk factors: one-year results of the PREDIMED-plus trial. Diabetes Care. 2019;42:777-788. doi:10.2337/dc18-0836

28. Lindsey L, Husband A, Steed L, Walton R, Todd A. Helpful advice and hidden expertize: pharmacy users' experiences of community pharmacy accessibility. J Public Health. 2017;39:609-615. doi:10.10 93/pubmed/fdw089

29. Seidling HM, Send AFJ, Bittmann J, et al. Medication review in German community pharmacies - post-hoc analysis of documented drug-related problems and subsequent interventions in the ATHINA-project. Res Social Adm Pharm. 2017;13:1127-1134. doi:10.1016/j.sapharm.2016.10.016

30. Kempen TGH, van de Steeg-van Gompel CH, Hoogland P, Liu Y, Bouvy ML. Large scale implementation of clinical medication reviews in Dutch community pharmacies: drug-related problems and interventions. Int J Clin Pharm. 2014;36:630-635. doi:10.1007/ s11096-014-9947-4

31. Szilvay A, Somogyi O, Meskó A, Zelkó R, Hankó B. Qualitative and quantitative research of medication review and drug- related problems in Hungarian community pharmacies: a pilot study. $B M C$ Health Serv Res. 2019;19:282. doi:10.1186/s12913-019-4114-1

32. Lewinski D, Wind S, Belgardt C, Plate V, Behles C, Schweim HG. Prevalence and safety-relevance of drug-related problems in German community pharmacies. Pharmacoepidemiol Drug Saf. 2010;19 (2):141-149. doi:10.1002/pds.1861

33. National Institute for Health and Care Excellence. Gastrooesophageal reflux disease and dyspepsia in adults: investigation and management (NICE Clinical guideline [CG184]). 2019. Available from: https://www.nice.org.uk/guidance/cg184. Accessed November 13, 2019.

34. Bush J, Langley C, Mills S, Hindle L. A comparison of the provision of the my choice weight management programme via general practitioner practices and community pharmacies in the United Kingdom. Clin Obes. 2014;4(2):91-100. doi:10.1111/cob.12049

35. Morton K, Pattison H, Langley C, Powell R. A qualitative study of english community pharmacists' experiences of providing lifestyle advice to patients with cardiovascular disease. Res Social Adm Pharm. 2015;11(1):e17-e29. doi:10.1016/j.sapharm.2014.04.006
Patient Preference and Adherence

\section{Publish your work in this journal}

Patient Preference and Adherence is an international, peer-reviewed, open access journal that focusing on the growing importance of patient preference and adherence throughout the therapeutic continuum. Patient satisfaction, acceptability, quality of life, compliance, persistence and their role in developing new therapeutic modalities and compounds to optimize clinical outcomes for existing disease states are major areas of interest for the journal. This journal has been accepted for indexing on PubMed Central. The manuscript management system is completely online and includes a very quick and fair peer-review system, which is all easy to use. Visit http:// www.dovepress.com/testimonials.php to read real quotes from published authors. 